Traveling health-promoting infrastructures

\title{
A meta-ethnographic analysis
}

Andersen, Signe Lindgård; Andersen, Ove; Petersen, Janne; Wahlberg, Ayo

Published in:

Health: An interdisciplinary journal for the social study of Health, Illness and Medicine

DOI:

$10.1177 / 1363459319829195$

Publication date:

2020

Document version

Peer reviewed version

Citation for published version (APA):

Andersen, S. L., Andersen, O., Petersen, J., \& Wahlberg, A. (2020). Traveling health-promoting infrastructures:

A meta-ethnographic analysis. Health: An interdisciplinary journal for the social study of Health, Illness and Medicine, 24(5), 606-622. https://doi.org/10.1177/1363459319829195 
This paper (post-print) has been accepted for publication in Health: An Interdisciplinary Journal for the Social Study of Health, IIlness and Medicine. Edited, revised and typeset version of this paper will be published in Health: Vol. 24 by Sage, All rights reserved. (C) Sage, 2019

\section{Travelling Health-promoting Infrastructures}

\section{A Meta-ethnographic Analysis of Qualitative Literature}

Signe Lindgaard Andersen (Copenhagen University Hospital, Denmark; University of Copenhagen, Denmark), Ove Andersen (Copenhagen University Hospital, Denmark), Janne Petersen (Bispebjerg and Frederiksberg Hospital, Denmark; Copenhagen University Hospital, Denmark; University of Copenhagen, Denmark) \& Ayo Wahlberg (University of Copenhagen, Denmark)

\section{Abstract}

In recent years, it has become increasingly important to understand the global circulation of healthcare innovations in nations' attempts to solve contemporary health challenges. This article is a systematic review and meta-ethnography-inspired analysis that explores the global circulation of health-related standards, protocols, procedures, and regulations, or what we term healthpromoting infrastructures (HPIs). The notion of HPIs is defined as built networks that allow for the circulation of health expertise with the intention of promoting solutions that address global health problems. We conducted systematic searches in six relevant electronic databases and ended up with a set of 13 studies. The review shows that it takes arduous work to prepare and facilitate the travel of HPIs and to mold them into meaningful local forms. In conclusion, we argue to think of HPIs as scripted forms which are globally available in always sited efforts to address specific problems.

Keywords: infrastructures, healthcare, standards, globalization, meta-ethnography 
This paper (post-print) has been accepted for publication in Health: An Interdisciplinary Journal for the Social Study of Health, IIlness and Medicine. Edited, revised and typeset version of this paper will be published in Health: Vol. 24 by Sage, All rights reserved. (C) Sage, 2019

\section{Introduction}

In recent years, the global circulation of healthcare innovations has intensified as nations attempt to address and solve their health challenges. It has therefore become increasingly important for policy makers, innovators, and health practitioners to understand what shapes the global flows of people, objects, expertise, and ideas in relation to healthcare. It is little wonder then that the global circulation of healthcare innovations has become a major academic research area in itself (Inhorn, 2015, 2003; Knecht et al., 2012; Lakoff, 2005; Ong and Chen, 2010; Petryna et al., 2006; Sunder Rajan, 2006; Wahlberg, 2018).

There is an extensive corpus of studies on medical travel or tourism - understood as people's transnational journeys for medical care and cures - as well as qualitative reviews of this literature (Connell, 2015; Inhorn, 2015; Kangas, 2010; Lunt and Carrera, 2010; Smith et al., 2011; Song, 2010). Less attention has been directed towards the movement of physicians, bio scientists, and nurses from low-income countries to the global North and vice-versa (Bradby, 2014; Prescott and Nichter, 2014; Waldby, 2009; Wendland, 2012). Scholarly attention has also been brought to bear on the accelerating global circulation of bio-objects (Vermeulen et al., 2012) such as organs, tissues, gametes, and genetic material (Hoeyer, 2013; Marshall and Daar, 2000; Scheper-Hughes, 2000, 2005; Waldby and Mitchell, 2006) as well as the global spread of pharmaceuticals and their "social lives" (Whyte et al., 2002) in various contexts (Hardon and Dilger, 2011; Petryna et al., 2006; Sjaak van der Geest et al., 1996; Whyte et al., 2004). Perhaps the least empirical attention 
This paper (post-print) has been accepted for publication in Health: An Interdisciplinary Journal for the Social Study of Health, IIlness and Medicine. Edited, revised and typeset version of this paper will be published in Health: Vol. 24 by Sage, All rights reserved. (C) Sage, 2019

has been directed towards the travel of material medical technologies, e.g. medical devices such as prosthetic limbs and implants, CT scans, and cardiac pacemakers (Hoeyer, 2009). ${ }^{1}$

Notwithstanding this social scientific attention to patients' medical travel, movement of healthcare professionals and flows of bio-objects, pharmaceuticals, and medical devices, no attempts have been made to synthesize the existing social scientific knowledge on a fourth major research area: that of the global circulation of health-related standards, protocols, procedures, and regulations, or what we term health-promoting infrastructures. This article develops this concept in the context of a systematic review and meta-ethnographic analysis of literature that offers perspectives on how such infrastructures travel across borders.

The interest in synthesizing knowledge from this area of research originates from SLA's PhD study, which explores how a Danish perioperative approach known as Fast-Track Surgery (FTS) (Kehlet and Wilmore, 2008) has traveled from a hospital in Denmark to hospitals in China. The FTS approach is a multimodal method that uses a combination of evidence-based interventions and standards to expedite recovery after surgery (Kehlet and Wilmore, 2008). As such, FTS cannot be adequately described in terms of the material objects, healthcare professionals, or patients that it works through; rather, it is a health-promoting infrastructure that is better understood in terms of a set of standardized procedures and protocols which bring together various sets of health expertise. With the FTS approach in mind and by developing a variant of Noblit and Hare`s metaethnographic methodology (1988), we review 13 ethnographic studies that shed light on how protocolled medical procedures, health management systems, and research regulations travel

\footnotetext{
${ }^{1}$ We are fully aware that the concept of technology has multi-faceted meanings ranging from notions of social technology, to human technology to material technology and that indeed some of these definitions could well be used in a similar way that we are proposing to use HPIs. But for the purpose of this review, we are limiting our definition of material technology to refer to medical devices.
} 
This paper (post-print) has been accepted for publication in Health: An Interdisciplinary Journal for the Social Study of Health, IIlness and Medicine. Edited, revised and typeset version of this paper will be published in Health: Vol. 24 by Sage, All rights reserved. (C) Sage, 2019

cross-border. As such, our synthesis of qualitative research is as interpretative as any ethnographic account (Noblit and Hare, 1988: 11) and should not be perceived primarily as an exercise in aggregating knowledge.

In an attempt to construct adequate interpretative explanations across very diverse qualitative material, it became relevant to think through the analytical notion of health-promoting infrastructures (HPIs), a novel contribution of this article. HPIs emerged from the interpretative work of the review process itself, as we will elaborate on in the methods section. Building on the work of Brian Larkin (2013) and Andrew Barry (2006), we define HPIs as built networks that allow for the circulation of (sets of) health expertise in the form of protocols, procedures, standards, and guidelines with the intention of promoting solutions to global health problems. ${ }^{2} \mathrm{HPIs}$ are not necessarily synonymous with success and better health for the world's population; what they do have in common is an explicit promotion of solutions to contemporary global health problems. Hence, they never guarantee more or better health and indeed very often fail. HPIs are an example of what Larkin has defined as "built networks that facilitate the flow of goods, people, or ideas and allow for their exchange over space... They comprise the architecture for circulation, literally providing the undergirding of modern societies" (Larkin, 2013: 328). Infrastructures that are health-promoting rely on material and immaterial fabric, consisting as they do of material core components such as documents, equipment and medical technologies that come into being as protocols, standards, regulations, and procedures. HPIs also entail immaterial core components such as expertise, standardized practices, and know-how that is exchanged and taught through

\footnotetext{
${ }^{2}$ It should be noted that our use and definition of HPIs is "restricted" to a delimited set of standards, protocols, guidelines or regulations (e.g. treatment protocols, bioethical guidelines for research or healthcare quality management systems) which brings certain (sets of) health expertise together. Our analysis shows that the circulation of HPIs is made possible by mobility infrastructures, including global air transportation systems, information and communication technology networks, and education systems that, at a minimum facilitate the use of English as a global language.
} 
This paper (post-print) has been accepted for publication in Health: An Interdisciplinary Journal for the Social Study of Health, IIlness and Medicine. Edited, revised and typeset version of this paper will be published in Health: Vol. 24 by Sage, All rights reserved. (C) Sage, 2019

training sessions, workshops, and various types of steering and committee meetings as structured parts of the HPI. Likewise, HPIs take a specific standardized form similar to what Barry (2006) has described with the notion of technological zones which he defines as "space within which differences between technical practices, procedures, and forms have been reduced, or common standards have been established" (Barry, 2006: 239). HPIs comprise shared, standardized forms as guiding norms for a given set of practices that "aim to render the world equivalent across cultures, time, and geography" (Timmermans and Epstein, 2010: 70). Drawing on the metaphor of "travelling comparisons" (Mohacsi and Morita, 2013: 176), HPI's mobility is strongly related to their ability to invoke comparisons and contrasts on many levels that emerge through connections and human relationships. Consequently, as HPIs travel, they engage many different relations and networks and can be redefined, adapted, modified, dismantled or ignored as they are mobilized in a particular context of use.

In this systematic review and meta-ethnographic synthesis, we intend to capture some of the complexities that inhere in the global flows of HPIs and raise the following questions: What drives HPIs to travel cross-border? How do HPIs travel? In which ways do HPIs take form in various contexts?

In the remaining sections of this article, we first address the methodology underlying this systematic review: a variant of meta-ethnography (Noblit and Hare, 1988) that favors interpretation over standardized techniques in review work. Each of three subsequent sections relates to one of the above research questions. The article presents two findings. First, arduous work is needed to prepare and facilitate the travel of HPIs and to mold them into meaningful local forms. Second, scholars must grant equal weight to the sites involved in the travel of HPIs and 
This paper (post-print) has been accepted for publication in Health: An Interdisciplinary Journal for the Social Study of Health, IIlness and Medicine. Edited, revised and typeset version of this paper will be published in Health: Vol. 24 by Sage, All rights reserved. (C) Sage, 2019

should be guided by the problem that initiates HPIs' travel rather than being seduced by the analytical distinction of sites of "origin" and "arrival."

\section{Methodology}

In this section, while presenting the method used, we engage with the question of how we can learn from existing qualitative literature. Meta-ethnography is the key inspirational framework for this review article; a method that was developed in education research by George W. Noblit and R. Dwight Hare (1988). The method emphasizes an interpretive approach where the aim is not merely an aggregation of evidence on a topic of interest, but to achieve a new grasp on that topic. The method has been used and evaluated extensively within health research (Britten et al., 2002; Campbell et al., 2003; Lafarge et al., 2014; Lee et al., 2015; Pound et al., 2005). Despite the method's originally explorative and interpretative nature, most meta-ethnographic efforts tend to conform to a technical set of sorting (see Thorne, 2017 for a similar point). In contrast to this trend, we propose a variant of meta-ethnography that mobilizes experimental and innovative review processes through repetitive and active reading. We developed two analytical strategies as they became meaningful in the iterative processes of interpretation and conceptual development.

\section{Literature search and selection of studies}

We conducted systematic searches in Scopus, Web of Science, IBSS, Francis, Sociological abstracts, and Anthropology Plus. We developed a search string after experimenting with key words and different combinations of key words. The final search string reflects our interest in learning from qualitative and ethnographic studies on how health-related standards, protocols, procedures, and 
This paper (post-print) has been accepted for publication in Health: An Interdisciplinary Journal for the Social Study of Health, IIlness and Medicine. Edited, revised and typeset version of this paper will be published in Health: Vol. 24 by Sage, All rights reserved. (C) Sage, 2019

regulations, travel cross-border. In the search string, the words "pharmaceutical" and "drug" may seem to deviate from this interest. However, inclusion of these two words yielded literature that concerns travelling regulatory frameworks, standards, and protocols that facilitate pharmaceutical companies' activities around the globe. Moreover, we went through the bibliographies of the literature we found and asked authors about what other relevant studies we should look at. We also searched a considerable number of anthologies for relevant chapters.

The definition of the inclusion criteria was an on-going process in parallel with developing the search string, reading abstracts, and selecting cases. The criteria mirror our interest in the travelling processes of HPIs. Several studies were excluded because they explore the HPI upon "arrival" in a new context of use and the processes of re-contextualization (Inhorn, 2003; Meinert et al., 2009; Simpson and Sariola, 2012). Included studies must address aspects of the microprocesses that shape the travel of HPIs and should add knowledge to a minimum of two out of the three research questions. Further, we emphasized the quality of the time the researcher has devoted to activities such as participant observation, informal conversation, and interviews rather than the length of fieldwork in itself. Applying our inclusion and exclusion criteria, we ended up with a set of 13 studies. We recognize that this relatively small set of studies inevitably creates a too-narrow foundation for generalizations. However, the purpose of this review article is not to deliver an exhaustive aggregation of the entire body of available knowledge in order to generalize, but rather to construct a window through which we could develop conceptual understandings of how health-related standards, protocols, procedures, and regulations travel across borders.

The 13 studies consist of seven articles, one book chapter and four chapters from anthologies. The studies were published in the years 2005-2016, thus emphasizing that it is a recent yet well- 
This paper (post-print) has been accepted for publication in Health: An Interdisciplinary Journal for the Social Study of Health, IIlness and Medicine. Edited, revised and typeset version of this paper will be published in Health: Vol. 24 by Sage, All rights reserved. (C) Sage, 2019

established topic, and also a timely moment for our review. The studies have been authored by anthropological or sociological scholars and are ethnographic in their methodological approach. The studies present great diversity with different analytical aims, describing different contexts, investigating different types of HPIs, and drawing on a wide range of anthropological, sociological, and STS-inspired theoretical concepts for analytical purposes. The diverse material was a challenge in the meta-ethnographic analysis, but also what ultimately nurtured the development of the notion of HPIs through a line of argument synthesis.

\section{The meta-ethnographic analysis, reading(s), and the "birth" of HPIs}

In this meta-ethnographic synthesis, we develop a line of argument synthesis that involves two iterative phases: a translation of the studies into one another, followed by placing the similarities and differences among the studies into an interpretative order (Noblit and Hare, 1988: 64). A line of argument synthesis is a meta-ethnographic activity in which separate parts are brought together to form a "whole." This construction of the whole is essentially characterized by some degree of innovation so that the result goes beyond the content of the original studies developing an over-arching interpretation (Noblit and Hare, 1988). The "whole" in this line of argument synthesis is the notion of health-promoting infrastructures.

In most descriptions of meta-ethnographic synthesis, the activity of reading is not given much attention (Lee et al., 2015). However, repetitive readings of the material pervaded our entire process. Much in line with Lee et al., "intensive, repetitive, and above all highly active reading...was at the very heart of the meta-ethnographic process" (Lee et al., 2015: 341).

As Noblit and Hare recognize, reading is not easily confined to one particular phase (Noblit and Hare, 1988). Our continuous readings reflect this point taking place at different stages in the 
This paper (post-print) has been accepted for publication in Health: An Interdisciplinary Journal for the Social Study of Health, IIlness and Medicine. Edited, revised and typeset version of this paper will be published in Health: Vol. 24 by Sage, All rights reserved. (C) Sage, 2019

process with very different aims, among others to appraise, to familiarize, to identify, to categorize, to compare, to organize, to document, and to verify.

In the early phases of the analysis, the reading was facilitated by employing a technique to organize the knowledge from the diverse studies. A document was created for each of the studies, and the studies were read through the lens of how they added knowledge to the three research questions. This resulted in 13 small accounts of the studies and enabled the process of identifying key metaphors and themes (Noblit and Hare, 1988: 14). The small accounts pointed to five major themes in relation to the traveling processes of HPIs and revealed not only similarities and differences, but also the high complexity that characterized their travel. At this point, the idea of health-promoting infrastructures emerged in our attempt to think across this complexity and gain traction within diverse ethnographic material.

To define HPIs, the research team developed a table that came to be crucial. The table, more than an overview of each of the included studies, is part of the analysis and as such an interpretation disclosing how HPIs materialized in each of the reviewed studies. Re-reading the studies, we identified the different types of HPIs and categorized them into two major categories: patientrelated and clinical research-related. Within each category, five HPI subcategories are identified: management systems in relation to chronic diseases (Nielsen, A.J. and Langstrup, H., 2014; Nielsen \& Jensen, C.B., 2013; Rogvi et al., 2016); treatment procedures and protocols to assist reproduction and overcome infertility (Simpson 2012, Hörbst 2012); systems in relation to hospital management (Bruun Jensen, 2010); research regulations and protocols for developing new biomedical treatments (Kuo, 2009; Petryna, 2007b; Rosemann, 2014; Sunder Rajan, K., 2010); and bioethical regulatory frameworks for clinical research to promote safe and ethical drug 
This paper (post-print) has been accepted for publication in Health: An Interdisciplinary Journal for the Social Study of Health, IIlness and Medicine. Edited, revised and typeset version of this paper will be published in Health: Vol. 24 by Sage, All rights reserved. (C) Sage, 2019

development (Petryna, 2005, 2007a; Sariola and Simpson, 2011). Further, through focused reading, we identified the health-promoting goal in each of the studies and mapped out the core components of each HPI.

Through reading with various purposes in mind and inventing necessary techniques along the way, we identified similarities, differences, and complexities in the travel of HPIs and integrated these into a line-of-argument synthesis, launching the theoretical notion of HPIs in the process.

\section{Analysis}

Our meta-ethnographic synthesis is divided into three sections; one for each research question.

The three sections cover five major themes from the analysis: the idea of universal applicability, HPI drivers, transnational encounters, zones of friction, and re-innovation of HPIs.

\section{What drives HPIs to travel cross-border?}

In this section, we explore what motivates the travel of HPIs. We argue that mobility and transferability are built into the logic of HPIs and show that a context that includes complex surroundings of needs, demands, political and economic interests, and scientific ambitions all affects the travel of HPIs.

\section{The idea of universal applicability}


This paper (post-print) has been accepted for publication in Health: An Interdisciplinary Journal for the Social Study of Health, IIlness and Medicine. Edited, revised and typeset version of this paper will be published in Health: Vol. 24 by Sage, All rights reserved. (C) Sage, 2019

In the reviewed literature, the HPIs - management systems, clinical research regulations and protocols and treatment procedures - share universal aspirations. The HPIs are claimed to be evidence-based, global and standardized. They embed knowledge, practices, measures, properties, techniques, and terminologies that are claimed to be universally applicable. These universal aspirations are closely related to processes of "scripting" (Akrich, 1992), a concept that three STS-studies borrow explicitly (Nielsen, A.J. and Langstrup, H., 2014; Nielsen and Jensen, C.B., 2013; Rogvi et al., 2016).

Anne J. Nielsen and Casper B. Jensen's (2013) analysis of implementing the Stanford Chronic Disease Self-Management Program (CDSMP) as a new type of patient education in Denmark is an important example of this. They show how CDSMP could travel to Denmark by after the program was transformed from an "un-theorized, "experiential" entity, into a theorized, evidence-based one" (Nielsen and Jensen, C.B., 2013: 67-68). This transformation involved creating a comprehensive script that interconnected every part of the program into a standardized whole. In this sense, HPIs can be said to be "scripted packages" (Nielsen and Jensen, C.B., 2013) that have been carefully prepared to include universal language that makes cross-cultural travel possible. The HPIs have transferability in terms of this built-in scripted protocol and standardized form that grants them the ability to travel cross-border. In their study of a Danish quality assurance software system for managing diabetes, Sofie á Rogvi et al. point out that:

"The idea of universality is reflected in the notion of transferability, for example, that health technologies or knowledge can travel (and be relevant) between contexts and that a need in one place can be fulfilled by an intervention from another" (Rogvi et al., 2016: 251). 
This paper (post-print) has been accepted for publication in Health: An Interdisciplinary Journal for the Social Study of Health, IIlness and Medicine. Edited, revised and typeset version of this paper will be published in Health: Vol. 24 by Sage, All rights reserved. (C) Sage, 2019

The implicit notion is therefore that HPIs travel because they are understood to be solutions for pre-defined and pre-existing problems. However, as Casper Bruun Jensen points out, need is not a static entity, but dynamic and transformational (Bruun Jensen, 2010: 55). Similarly, Rogvi et al. (2016) show empirically that neither a problem nor a need is a pre-existing entity. Rogvi et al. investigate how the needs for a specific software system for monitoring diabetes treatment quality were constituted through the very process of moving the software from Denmark to Indonesia. Here the need is redefined and displaced as new users in Indonesian clinics do not behave in accordance with the particularly crafted form of quality assurance in the software. Despite universal aspirations, exogenously defining what other people need "is not a neutral act but charged with valorizations and categorizations, with implicit imaginings of what constitutes the 'good' and how to obtain it" (Rogvi et al., 2016: 251). Thus, Rogvi et al. move our focus away from the tendency to think about the construction of solutions to pre-defined problems or needs as essential for initiating the travel of HPIs. Rather, they call for attention to the construction of problems (and needs), thus enrolling others to (re)define and mobilize the HPI according to certain problems that gain primacy over other problems in specific sites.

\section{Drivers of HPIs}

The reviewed studies portray a diverse and complex picture of driving forces that fuel the crossborder travel of HPIs. These driving forces do not simply reflect a Global South in need of the Global North's health expertise, but must be understood by including the various and dynamic environments of needs/demands, economic and political interests, and scientific ambitions that the HPIs are embedded within. 
This paper (post-print) has been accepted for publication in Health: An Interdisciplinary Journal for the Social Study of Health, IIlness and Medicine. Edited, revised and typeset version of this paper will be published in Health: Vol. 24 by Sage, All rights reserved. (C) Sage, 2019

This diversity of driving forces is clear in the numerous studies on the emergence of a global clinical trial landscape of industry-sponsored forms of clinical research on vaccines and drugs (Petryna, 2005, 2007a, 2007b; Rosemann, 2014; Sariola and Simpson, 2011; Sunder Rajan, K., 2010). Adriana Petryna describes various market forces that fuel the off-shoring of clinical research regulations and protocols from the United States to Eastern Europe and Latin America (Petryna, 2005: 185, 2007a: 25, 2007b). This outsourcing is driven in part by an increase in the number of trials and the growth of commercial organizations facilitating drug trials for profit. Even more, the pressure to secure large numbers of research subjects quickly, combined with a shrinking pool of research subjects, leads pharmaceutical companies offshore clinical trials to regions where regulatory standards are lower. Here the travel of clinical research regulations and protocols is motivated by Western countries that are in need of human subjects from the East (Petryna, 2005: 185).

More importantly, this need for human subjects propelled a necessity for American and European standards and regulations to become transferable and applicable cross-border leading to the establishment of regulatory platforms like the International Conference on Harmonization (ICH) (Kuo, 2009; Petryna, 2005) and The Comité Européen de Normalisation (CEN) (Bruun Jensen, 2010). For instance, throughout the 1990s, international harmonization of trial procedures was carried out to ensure the safety and quality of drug development by regulatory experts and authorities from Europe, USA and Japan under the aegis of ICH (Petryna, 2005: 185, Kuo, 2009: 55-57). Thus, the need for human subjects, as a driver for research-related HPIs to travel from the West to the East, was simultaneously a catalyst for the international harmonization wave ensuring HPIs to be mobile and to make international research sites transferable. 
This paper (post-print) has been accepted for publication in Health: An Interdisciplinary Journal for the Social Study of Health, IIlness and Medicine. Edited, revised and typeset version of this paper will be published in Health: Vol. 24 by Sage, All rights reserved. (C) Sage, 2019

Petryna raises questions about the unequal social context in which research is being performed and how conditions of inequality create settings for human exploitation (Petryna, 2005, 2007a). Commenting on Petryna's work, Wen-Hua Kuo (2009) and Kaushik Sunder Rajan (2010) point out that it is important to be careful when applying a general image of populations as guinea pigs for international pharmaceutical companies' clinical trials (Kuo, 2009: 58; Sunder Rajan, K., 2010: 68). In Kuo's study of Taiwan's engagement with global pharmaceutical regulation, Taiwan seizes the opportunity to be the first non-ICH (International Committee on Harmonization) state to follow the ICH guidelines, constituting a great leap toward the country becoming a center for clinical trials in Asia and to be allowed in on the international scene of drug regulation (Kuo, 2009: 63). Kuo's analytical starting point is not to perceive Taiwan as a passive and victimized recipient that lays house to exploitation of its citizens. On the contrary, Kuo pursues the analytical grip that Taiwan is an active, powerful actor with its own political agenda dismantling the idea of East Asian countries as weak states.

We learn from the literature, that HPIs become political tools to achieve higher purposes such as attracting investment, building research capacities, boosting economies, providing public healthcare and participating in global scientific advances (Kuo, 2009; Petryna, 2005; Simpson, 2012; Sunder Rajan, K., 2010). This feeds into our argument that the travel of HPIs is initiated by problems blurring the distinction of "origin" and "arrival" and rejecting the common unidirectional mode of HPIs travelling from the Global North to the Global South.

\section{How do HPIs travel?}


This paper (post-print) has been accepted for publication in Health: An Interdisciplinary Journal for the Social Study of Health, IIlness and Medicine. Edited, revised and typeset version of this paper will be published in Health: Vol. 24 by Sage, All rights reserved. (C) Sage, 2019

This section explores how HPIs travel and the plurality of actors and activities that it entangles.

HPIs do not travel by themselves, it entails hard work and only takes place with great effort.

\section{Transnational encounters}

To begin with, human involvement and collaborative establishments of links and global partnerships are required for HPIs to move cross-border. In the reviewed literature, collaborative establishments involve a plurality of actors such as health professionals, medical experts, health institutions, companies, international organizations, the pharmaceutical industry, and nation states. These actors engage in a broad range of transnational activities including conferences, workshops, training programs, supervision, capacity building, technical support, expert meetings, and monitoring missions. HPIs travel very differently through these various transnational activities that exist on both a personal and an organizational level.

The studies on the dissemination of assisted reproductive technologies into harsh political environments in third world countries offer great insight into the importance of personal relations and key individuals for HPIs to travel cross-border (Hörbst, 2012; Simpson, 2012). For example, Bob Simpson (2012) reconstructs the struggles evoked in cultivating a nationally applicable regulation of reproductive technologies in Sri Lanka through the stories of the British embryologist, Dr. Simon Fishel's engagement with a local clinic. At the outset, Dr. Fishel provided the clinic with support, training, and advice on how the clinic and important stakeholders could proceed with the establishment of in vitro fertilization (IVF) treatment within proper regulatory frameworks and following good protocols. However, with time, the collaboration with Dr. Fishel came to serve as a powerful statement of international linkage and legitimacy to the clinics' work with IVF in an otherwise non-supportive political environment (Simpson, 2012: 74). In a similarly 
This paper (post-print) has been accepted for publication in Health: An Interdisciplinary Journal for the Social Study of Health, IIlness and Medicine. Edited, revised and typeset version of this paper will be published in Health: Vol. 24 by Sage, All rights reserved. (C) Sage, 2019

difficult political environment, Viola Hörbst (2012) tells the story of an entrepreneurial minded Malian gynecologist, Dr. M and his single-handed struggle to access technological skills, and reproductive equipment through transnational connections and private contacts. As such, Dr. Fishel and Dr. M. are key interlocutors who, through personal encounters, promote reproductive technologies, keep them in place, and move them forward. It is through such encounters, characterized by personal involvement and pioneering spirit, that HPIs can travel.

Workshops, education, and training activities are another type of more formalized transnational activities through which HPIs travel (Hörbst, 2012; Nielsen, A.J. and Langstrup, H., 2014; Nielsen \& Jensen, C.B., 2013; Rogvi et al., 2016; Rosemann, 2014). In Rogvi et al.'s study (2016), Danish experts educate Indonesian general practitioners in the use of the Danish quality-monitoring software (DQMS) in a workshop in Jakarta. By the end of the workshop, Indonesian participants understood both that they shared the challenge of a global rise in diabetes with Denmark and that a Danish approach to diabetes treatment, DQMS, could be deployed in Indonesia as well (Rogvi et al., 2016: 256-7). In Achim Roseman's (2014) analysis of the formation of the China Spinal Cord Injury Network (China SCI Net), a training program for staff members was initiated to adjust local clinical practices to internationally recognized research standards. Apart from attempting to standardize clinical practice, the training and monitoring activities also revealed local conditions and challenges that worked against this undertaking (Rosemann, 2014: 75).

In general, capacity building is an important transnational activity through which HPIs travel. In the reviewed literature on the movement of research-related HPIs, these encounters often existed on an organizational level and are described from a political and regulatory perspective (Kuo, 2009; Petryna, 2005, 2007a, 2007b; Sunder Rajan, K., 2010). Sunder Rajan (2010) analyzes a range of 
This paper (post-print) has been accepted for publication in Health: An Interdisciplinary Journal for the Social Study of Health, IIlness and Medicine. Edited, revised and typeset version of this paper will be published in Health: Vol. 24 by Sage, All rights reserved. (C) Sage, 2019

interlocutors that interact in the efforts to build up regulatory frameworks that strengthen India's profile as an attractive site for outsourced clinical trials. Contract Research Organizations (CROs), the Indian Pharmaceutical industry, Indian regulators, and the Indian state are all involved in a massive harmonization process that seeks to standardize Indian laws with international protocols (Sunder Rajan, K., 2010: 67).

HPIs travel very differently through various transnational links and activities. Not only do HPIs forge and negotiate complex personal and organizational relationships, but these relationships also serve the purpose of identifying needs and problems as well as establishing authority and authenticity in the travel of HPIs.

\section{In which ways do HPIs take form in various contexts?}

This section explores how HPIs are mobilized into new contexts of use and how they, through frictional and comparative encounters, get molded and reinvented into new versions.

\section{Frictional and comparative encounters}

It is well-established in the reviewed literature that HPIs travel along bumpy roads. All 13 studies document transnational encounters that facilitated the emergence of HPI travel frictions in the form of differences between global/universal aspirations of an HPI and a new reality. Such friction shows that HPIs are not neutral "transporters" of universal healthcare, but carry a heavy load of assumptions about e.g., patients, organizational structures, needs, and healthcare systems. For example, Western ideas about personhood cause friction as they rub against a clinical situation in 
This paper (post-print) has been accepted for publication in Health: An Interdisciplinary Journal for the Social Study of Health, IIlness and Medicine. Edited, revised and typeset version of this paper will be published in Health: Vol. 24 by Sage, All rights reserved. (C) Sage, 2019

Sri Lanka where decision making resides within a set of family relations (Sariola and Simpson, 2011: 517-18).

Several studies work analytically with frictional encounters referring to Anna Tsing's (Tsing, 2005) notion of friction as a metaphor for diverse and conflicting interactions that make up global encounters (Hörbst, 2012; Nielsen, A.J. and Langstrup, H., 2014; Nielsen and Jensen, C.B., 2013; Rogvi et al., 2016). One important point to draw from these studies is that frictions should not necessarily be seen as unsuccessful attempts to transfer HPIs. Rather, the frictions can be productive in nature and involve "difference-based interactions" rather than conflict per se (Nielsen, A.J. and Langstrup, H., 2014 cited from Tsing, 2005: 707). Frictions form the basis for comparison as the HPIs become a "lens for comparison" (Rogvi et al., 2016: 257) that illuminates the differences and similarities between the place of origin and the new context of use (Nielsen, A.J. and Langstrup, H., 2014; Nielsen \& Jensen, C.B., 2013; Rogvi et al., 2016). HPIs compare for example different ideas of personhood (Sariola and Simpson, 2011), patient roles (Nielsen \& Jensen, C.B., 2013), and health systems (Nielsen, A.J. and Langstrup, H., 2014; Rogvi et al., 2016).

\section{Reinvention of HPIs into new settings}

The zones of friction and comparison are a precondition for something to travel (Rogvi et al., 2016) as HPIs have to gain some kind of a grip or traction in a new context. The grip is further established through molding processes, where the people concerned with the HPI reinvent its script to address a site-specific problem in an attempt to render the HPI locally meaningful. For example, Nielsen and Langstrup (2014) describe how the DQMS script, which requires at least three months of data entry from 200 patients to have statistical power, does not adapt well to Indonesian clinics that might have only 20 diabetes patients in a 3-month period. Thus, Danish and Indonesian 
This paper (post-print) has been accepted for publication in Health: An Interdisciplinary Journal for the Social Study of Health, IIlness and Medicine. Edited, revised and typeset version of this paper will be published in Health: Vol. 24 by Sage, All rights reserved. (C) Sage, 2019

partners introduced a change in the script stating that Indonesian clinics no longer had to deliver statistically valid data from their monitoring. Consequently, the use of DQMS was changed from being a quality assurance tool to being connected to larger political aims such as creating a sustainable referral system and better relations between primary care and specialist care in Indonesian clinics (Nielsen, A.J. and Langstrup, H., 2014: 244-9). This example supports our finding that rather than HPIs serving as a solution to pre-defined problems, they travel dynamically as they become mobilized to solve a problem that gains primacy over other problems in specific sites.

Thus, HPIs become workable entities in a new context of use. This is also the key argument in Petryna's article on "ethical variability" in clinical trials, which suggests that ethical practices resolve differently in First and Third World countries (Petryna, 2005). With the example of azido thymidine trials and the Helsinki Declaration revisions, Petryna shows how recourse to local standards of care allow for-profit CROs to outsource clinical trials to lower-income countries where the CROs can bend the international ethics codes that protect human research subjects to their commercial and scientific advantage (Petryna, 2005: 189).

The reviewed literature presents another type of molding; one in which the HPIs come to exist parallel to current local health practices (Bruun Jensen, 2010; Rosemann, 2014). Rosemann points to a clinic in South China where experimental stem cell treatments were offered to patients in the context of clinical pilot studies, exterior to the hospital's involvement in the China Spinal Cord Injury Network's stem cell trials that adopted internationally recognized standards (Rosemann, 2014: 77). 
This paper (post-print) has been accepted for publication in Health: An Interdisciplinary Journal for the Social Study of Health, IIlness and Medicine. Edited, revised and typeset version of this paper will be published in Health: Vol. 24 by Sage, All rights reserved. (C) Sage, 2019

Based on these examples, we suggest that HPIs become malleable and workable entities as they are molded to fit into already existing healthcare practices in a new context addressing sitespecific problems.

In a new context of use, the HPIs fail all the time according to the script and intended goal of the original HPI. This does not mean that the HPIs are failures. However, sometimes the frictions can be unproductive and cause consequences such as inequality (Hörbst, 2012: 194; Simpson, 2012: 69) and exploitation of human subjects (Petryna, 2005, 2007a; Sunder Rajan, K., 2010: 70).

Occasionally, the HPI can fail to travel at all, mostly because of lack of state-engagement and situations of societal crisis (Hörbst, 2012; Petryna, 2005, 2007a; Rosemann, 2014; Simpson, 2012). Thus, while HPIs promote solutions to contemporary global health problems; they never guarantee success in that undertaking.

\section{Discussion: Revisiting the notion of HPIs and how they travel}

Our review shows that it takes arduous work to both prepare and facilitate the travel of HPIs and to mold them into meaningful national and local forms. This finding parallels those of various studies of science and technology that similarly document the difficulties in migrating technologies from one context to another (Akrich, 1992; de Laet, M. \& Mol, A., 2000; Morita, 2013; Schnitzler, 2013). These studies remind us of Zeynep Gürtin's (2012) observation, that there is a tendency to overstate the fluidity, abstractability, and movement of global forms, which "inadvertently eclipse[s] the very work often necessary to enable them to travel" (Gürtin B., 2012). We argue that the substantial efforts that go into turning a set of daily practices into a "scripted package" with 
This paper (post-print) has been accepted for publication in Health: An Interdisciplinary Journal for the Social Study of Health, IIlness and Medicine. Edited, revised and typeset version of this paper will be published in Health: Vol. 24 by Sage, All rights reserved. (C) Sage, 2019

assumed universal applicability are necessary for something to travel at all, a point also emphasized by other scholars (Barry, 2006; Petryna, 2009; Simpson and Sariola, 2012). Bob Simpson and Salla Sariola (2012) state that "without this work, the experimentation upon which progress in biomedical science depends will not travel and, even if it did, it would produce results that were neither valid nor transferable" (Simpson and Sariola, 2012: 556). Further, the strenuous efforts of a plurality of actors, both individual and organizational, engage in frictional and comparative encounters through a range of transnational activities as a precondition for the travel of HPIs. These transnational activities reveal a number of dynamic and pluri-directional exchanges between multiple contexts. As such, the findings of this review further undermine any unidirectional model of HPI travel from the Global North to the Global South (Wahlberg, 2018).

Our review showed how HPIs are unpredictable as they travel, and not least since as they encounter a particular context and set of health problems along the way: they become subject to experimentation in ways that lead to the development of new specific versions of the HPI. To draw a comparison with Bruno Latour's seminal concept of "immutable mobiles" (1986), which refers to machines designed to produce functionally comparable results in disparate domains, HPIs appear to be mutable rather than immutable mobiles; they take various shapes and never guarantee more or better health. In Latour's actor-network theory, immutable mobiles and their technological configurations are held together in a stable manner through a particular web of relations that are elaborated and performed. Despite their assumed universal configurations, however, HPIs exist in changing and dynamic networks led and configured by specific problems that make them unpredictable and "fluid." In their case study of the fluidity of the Zimbabwe Bush Pump, Annemarie Mol and Marianne de Laet (2000) show the flexibility of the bush pump and how it changes shape as it spreads far and wide in Zimbabwe. They argue that the pump`s travel is 
This paper (post-print) has been accepted for publication in Health: An Interdisciplinary Journal for the Social Study of Health, IIlness and Medicine. Edited, revised and typeset version of this paper will be published in Health: Vol. 24 by Sage, All rights reserved. (C) Sage, 2019

exempt from difficulties because its workings and boundaries change over time and space and results in multiple versions of the same bush pump. Whereas Mol and de Laet present the bush pump as a case of fluid adaptation and localization in a new context, we emphasize the fluidity and multiplicity of an $\mathrm{HPI}$ in relation to the problem that guides its numerous formations at various different sites.

In their influential work on standardization in healthcare, Timmermans and Epstein argue that "somewhere between glorified globalization and dark dehumanization, each standard achieves some small or large transformation of an existing order" (Timmermans and Epstein, 2010: 83). Similarly, HPIs appear to be generative to greater or lesser degrees rather than destructive and foster innovation and new ways to navigate an ever more complex healthcare system. However, apart from Petryna's work, the reviewed studies reveal very little on the unintended consequences and effects of HPIs. We suggest that future research engage analytically with the potentially destructive forces of HPIs and reflect upon what disappears and gets silenced as they get mobilized in new settings.

HPIs are as much global and universal entities as they are local. Indeed, so much so that distinctions between "origin" and "recipient" sites very quickly lose analytical traction. A key argument is that we should grant equivalent weight and analytical attention to each of the sites involved in the HPIs travel and turn the tables by reorienting our analyses of HPI travels by exploring in which ways and as part of the search for solutions to which problems traveling HPIs are mobilized in a particular setting? Similarly, Kuo (2009) sees Taiwan as an active agent with a problem of its own to solve - how to gain voice on the international market for drug development - rather than seeing Taiwan "merely" as a point of arrival and a passive recipient of ICH guidelines. Likewise, Wahlberg has argued that we need to study processes of routinization of medical 
This paper (post-print) has been accepted for publication in Health: An Interdisciplinary Journal for the Social Study of Health, IIlness and Medicine. Edited, revised and typeset version of this paper will be published in Health: Vol. 24 by Sage, All rights reserved. (C) Sage, 2019

technologies in so-called "recipient" countries rather than focus on globalization as such

(Wahlberg 2018). By reorienting our analytical perspective, we will see that there can be different problems and interests, irrespective of site and far from always altruistic in nature, that initiate the travel of an HPI depending on from which perspective one explores and tells the story. The great potential of thinking through the lens of HPIs is exactly that the notion allows us to blur the idea of origin. In a $21^{\text {st }}$ century marked by considerable infrastructural and technological development, the travel of HPIs is characterized by a myriad of connections and links taking multiple directions. As soon as they travel, HPIs take on a life of their own, becoming subject to experimentation and reinvention. Therefore, we suggest thinking of HPIs as scripted forms that are globally available for people to engage with and mobilize to address specific problems.

\section{Conclusion}

In this review, the notion of HPI offers a productive analytical lens that builds on the findings of the original studies and suggests a shift in the analytical take on travelling standards, protocols, procedures, and regulations. This shift involves giving equal analytical attention to the sites involved in an HPI's travel, including investigating how HPIs are mobilized in a particular country or setting as part of the search for solutions to specific problems. As various types of HPIs continue to spread across borders, we need continued scholarly attention to the various ways that HPIs travel, the goals that are brought into being, how they become entangled in multiple relationships and foster new ways of navigating increasingly complex health systems. Importantly, we still have much to learn about the unintended consequences and potentially destructive effects of HPIs. 
This paper (post-print) has been accepted for publication in Health: An Interdisciplinary Journal for the Social Study of Health, IIlness and Medicine. Edited, revised and typeset version of this paper will be published in Health: Vol. 24 by Sage, All rights reserved. (C) Sage, 2019

\section{Reference list}

Akrich M (1992) The De-scription of Technical Objects. In: Shaping Technology/Building Society: Studies in Sociotechnical Change. Cambridge, Ma: MIT Press, pp. 205-224.

Barry A (2006) Technological Zones. European Journal of Social Theory 9(2): 239-253.

Bradby $\mathrm{H}$ (2014) International medical migration: A critical conceptual review of the global movements of doctors and nurses. Health: 18(6): 580-596.

Britten N, Campbell R, Pope C, et al. (2002) Using meta ethnography to synthesise qualitative research: a worked example. Journal of Health Services Research \& Policy 7(4): 209-215.

Bruun Jensen C (2010) Traveling Standards. In: Ontologies for Developing Things: Making Health Care Futures Through Technology. Sense Publishers.

Campbell R, Pound P, Pope C, et al. (2003) Evaluating meta-ethnography: a synthesis of qualitative research on lay experiences of diabetes and diabetes care. Social Science \& Medicine 56(4): 671-684.

Connell J (2015) From medical tourism to transnational health care? An epilogue for the future. Social science and medicine 124: 398-401.

de Laet, M. \& Mol, A. (2000) The Zimbabwe Bush Pump: Mechianics of a Fluid Technology. Available at: http://journals.sagepub.com/doi/pdf/10.1177/030631200030002002 (accessed 24 January 2017).

Gürtin B. Z (2012) The Localization of IVF in Turkey. In: Reproductive Technologies as Global Form. Ethnographies of Knowledge, Practices, and Transnational Encounters. Campus Verlag.

Hardon A and Dilger H (2011) Global AIDS Medicines in East African Health Institutions. Medical Anthropology 30(2): 136-157.

Hoeyer K (2009) Tradable Body Parts? How Bone and Recycled Prosthetic Devices Acquire a Price without Forming a 'Market'. BioSocieties 4(2-3): 239-256.

Hoeyer K (2013) Exchanging human bodily material: rethinking bodies and markets. Dordrecht ; New York: Springer.

Hörbst V (2012) Assisted Reproductive Technologies in Mali: Asymmetries and Frictions. In: Reproductive Technologies as Global Form. Ethnographies of Knowledge, Practices, and Transnational Encounters. Campus Verlag.

Inhorn Marcia C. (2003) Global infertility and the globalization of new reproductive technologies: illustrations from Egypt. Social science \& medicine 56(9): 1837-1851.

Inhorn Marcia Claire (2003) Local babies, global science: gender, religion, and in vitro fertilization in Egypt. New York: Routledge.

Inhorn MC (2015) Cosmopolitan conceptions: IVF sojourns in global Dubai. Durham: Duke University Press.

Kangas B (2010) Traveling for medical care in a global world. Medical anthropology 29(4): 344-362. 
This paper (post-print) has been accepted for publication in Health: An Interdisciplinary Journal for the Social Study of Health, IIlness and Medicine. Edited, revised and typeset version of this paper will be published in Health: Vol. 24 by Sage, All rights reserved. (C) Sage, 2019

Kehlet $\mathrm{H}$ and Wilmore DW (2008) Evidence-based surgical care and the evolution of fast-track surgery. Annals of Surgery 248(2): 189-198.

Knecht M, Klotz M and Beck S (eds) (2012) Reproductive technologies as global form: ethnographies of knowledge, practices, and transnational encounters. Eigene und fremde Welten v. 19. Frankfurt ; New York: Campus Verlag.

Kuo W-H (2009) The Voice on the Bridge: Taiwan's Regulatory Engagement with Global Pharmaceuticals. 3(1): 51-72.

Lafarge C, Mitchell K and Fox P (2014) Termination of pregnancy for fetal abnormality: a meta-ethnography of women's experiences. Reproductive Health Matters 22(44): 191-201.

Lakoff A (2005) Pharmaceutical reason: knowledge and value in global psychiatry. Cambridge studies in society and the life sciences. Cambridge, UK ; New York: Cambridge University Press.

Larkin B (2013) The Politics and Poetics of Infrastructure. Annual Review of Anthropology 42(1): 327-343.

Latour B (1986) Visualization and cognition. Knowledge and society 6(6): 1-40.

Lee RP, Hart RI, Watson RM, et al. (2015) Qualitative synthesis in practice: some pragmatics of metaethnography. Qualitative Research 15(3): 334-350.

Lunt $\mathrm{N}$ and Carrera P (2010) Medical tourism: Assessing the evidence on treatment abroad. Maturitas 66(1): 27-32.

Marshall PA and Daar A (2000) Ethical issues in human organ replacement: a case study from India. In: Global health policy, local realities: the fallacy of the level playing field. Boulder, Colo: Lynne Rienner Publishers, pp. 205-30.

Meinert L, Mogensen HO and Twebaze J (2009) Tests for life chances: CD4 miracles and obstacles in Uganda. Anthropology and medicine 16(2): 195-209.

Mohacsi G and Morita A (2013) Traveling Comparisons: Ethnographic Reflections on Science and Technology. East Asian Science, Technology and Society 7(2): 175-183.

Morita A (2013) Traveling Engineers, Machines, and Comparisons: Intersecting Imaginations and Journeys in the Thai Local Engineering Industry. East Asian Science, Technology and Society: an International Journal 7(2): 221-241.

Nielsen, A.J. and Langstrup, H. (2014) Global Diabetes Encounters: Accounting for Health Technologies in the Global. In: The Global Politics of Science and Technology - Vol 2. Perspectives, Cases and Methods, pp. 235-251.

Nielsen \& Jensen, C.B. AJ (2013) Travelling Frictions: Global Disease Self-Management, Local Comparisons and Emergent Patients. Science \& Technology Studies 26(2): 61-79.

Noblit GW and Hare RD (1988) Meta-ethnography: synthesizing qualitative studies. Qualitative research methods v. 11. Newbury Park: Sage Publications. 
This paper (post-print) has been accepted for publication in Health: An Interdisciplinary Journal for the Social Study of Health, IIlness and Medicine. Edited, revised and typeset version of this paper will be published in Health: Vol. 24 by Sage, All rights reserved. (C) Sage, 2019

Ong A and Chen NN (eds) (2010) Asian biotech: ethics and communities of fate. Experimental futures : technological lives, scientific Arts, anthropological voices. Durham [NC]: Duke University Press.

Petryna A (2005) Ethical variability: Drug development and globalizing clinical trials. American Ethnologist 32(2): 183-197.

Petryna A (2007a) Clinical Trials Offshored: On Private Sector Science and Public Health. BioSocieties 2(1): 21-40.

Petryna A (2007b) Experimentality: On the Global Mobility and Regulation of Human Subjects Research. Political and Legal Anthropology Review 30(2): 288-304.

Petryna A (2009) When experiments travel: clinical trials and the global search for human subjects. Princeton: Princeton University Press.

Petryna A, Lakoff A and Kleinman A (2006) Global pharmaceuticals: ethics, markets, practices. Durham: Duke University Press.

Pound P, Britten N, Morgan M, et al. (2005) Resisting medicines: a synthesis of qualitative studies of medicine taking. Social Science \& Medicine 61(1): 133-155.

Prescott $\mathrm{M}$ and Nichter M (2014) Transnational nurse migration: Future directions for medical anthropological research. Social Science \& Medicine 107: 113-123.

Rogvi SA, Juul A and Langstrup H (2016) Generating Local Needs through Technology: Global Comparisons in Diabetes Quality Management. East Asian Science Technology and Society-an International Journal 10(3): 247-267.

Rosemann A (2014) Standardization as situation-specific achievement: Regulatory diversity and the production of value in intercontinental collaborations in stem cell medicine. Social Science \& Medicine 122: 72-80.

Sariola S and Simpson B (2011) Theorising the 'human subject' in biomedical research: International clinical trials and bioethics discourses in contemporary Sri Lanka. Social Science \& Medicine 73(4): 515-521.

Scheper-Hughes null (2000) The Global Traffic in Human Organs1. Current Anthropology 41(2): 191-224.

Scheper-Hughes N (2005) The last commodity: posthuman ethics and the global traffic in 'fresh' organs. In: Global Assemblages. Technology, Politics, and Etchis as Anthropological Problems. Blackwell Publishing, pp. 145-68.

Schnitzler AV (2013) TRAVELING TECHNOLOGIES: Infrastructure, Ethical Regimes, and the Materiality of Politics in South Africa. Cultural Anthropology 28(4): 670-693.

Simpson B (2012) Legacies and Linkages: Episodes in the Establishment of New Reproductive Technologies in Contemporary Sri Lanka. In: Reproductive Technologies as Global Form. Ethnographies of Knowledge, Practices and Transnational Encounters. Campus Verlag.

Simpson B and Sariola S (2012) Blinding Authority: Randomized Clinical Trials and the Production of Global Scientific Knowledge in Contemporary Sri Lanka. Science, Technology, \& Human Values 37(5): 555575. 
This paper (post-print) has been accepted for publication in Health: An Interdisciplinary Journal for the Social Study of Health, IIlness and Medicine. Edited, revised and typeset version of this paper will be published in Health: Vol. 24 by Sage, All rights reserved. (C) Sage, 2019

Sjaak van der Geest, Susan Reynolds Whyte and Hardon A (1996) THE ANTHROPOLOGY OF PHARMACEUTICALS: A Biographical Approach. Annual Review of Anthropology 25(1): 153-178.

Smith R, Martínez Álvarez M and Chanda R (2011) Medical tourism: A review of the literature and analysis of a role for bilateral trade. Health Policy 103(2-3): 276-282.

Song P (2010) Biotech Pilgrims and the Transnational Quest for Stem Cell Cures. Medical Anthropology 29(4): 384-402.

Sunder Rajan K (2006) Biocapital: the constitution of postgenomic life. Durham: Duke University Press.

Sunder Rajan, K. (2010) The Experimental Machine of Global Clinical Trials. Case studies from India. In: Asian Biotech.

Thorne S (2017) Metasynthetic Madness: What Kind of Monster Have We Created? Qualitative Health Research 27(1): 3-12.

Timmermans S and Epstein S (2010) A World of Standards but not a Standard World: Toward a Sociology of Standards and Standardization. Annual Review of Sociology 36(1): 69-89.

Toye F, Seers K, Allcock N, et al. (2014) Meta-ethnography 25 years on: challenges and insights for synthesising a large number of qualitative studies. BMC Medical Research Methodology 14: 80.

Tsing AL (2005) Friction: an ethnography of global connection. Princeton, N.J: Princeton University Press.

Vermeulen N, Tamminen S and Webster A (2012) Bio-objects: life in the 21st century. Theory, technology, and society. Burlington, VT: Ashgate.

Wahlberg A (2018) Good quality: the routinization of sperm banking in China. Oakland, California: University of California Press.

Waldby C (2009) Singapore Biopolis: Bare life in the city-state. East Asian Science, Technology and Society $3(2-3): 367-383$.

Waldby C and Mitchell R (2006) Tissue economies: blood, organs, and cell lines in late capitalism. Science and cultural theory. Durham [N.C.]: Duke University Press.

Wendland CL (2012) Moral Maps and Medical Imaginaries: Clinical Tourism at Malawi's College of Medicine. American Anthropologist 114(1): 108-122.

Whyte SR, Geest S van der and Hardon A (2002) Social lives of medicines. Cambridge studies in medical anthropology 10. Cambridge, UK ; New York: Cambridge University Press.

Whyte SR, Whyte MA, Meinert L, et al. (2004) Treating AIDS: dilemmas of unequal access in Uganda. SAHARA J: journal of Social Aspects of HIV/AIDS Research Alliance 1(1): 14-26. 
This paper (post-print) has been accepted for publication in Health: An Interdisciplinary Journal for the Social Study of Health, Illness and Medicine. Edited, revised and typeset version of this paper will be published in Health: Vol. 24 by Sage, All rights reserved. (C) Sage, 2019 